DOI: $10.24065 / 2237-9460.2020 v 10 n 1 I D 1473$

\title{
Formação, profissionalização e identidade docente do supervisor de estágio do curso de Fisioterapia
}

\author{
Dalianne Lobo da Costa' \\ Rosângela de Fátima Cavalcante França ${ }^{2}$ \\ José Lucas Pedreira Bueno ${ }^{3}$
}

\section{RESUMO}

Os contextos de atuação da área de Saúde exigem profissionais com formação generalista, conhecimentos técnico-científicos, postura ética, práticas humanizadas e com visão crítico-reflexiva. Partindo dessa premissa, esta pesquisa visou analisar a formação pedagógica do supervisor de estágio dos cursos de Fisioterapia, em Porto Velho/RO e as contribuições desse profissional para a formação dos fisioterapeutas, envolvendo também aspectos atinentes à identidade docente e à profissionalização. Trata-se de uma pesquisa descritivo-exploratória de abordagem qualitativa, realizada em duas Instituições de Ensino Superior (IES) privadas. Os resultados apontaram que a formação pedagógica para a supervisão de estágio se dava pela "autorreflexão da prática diária da preceptoria", no acompanhamento do contato direto dos estudantes com os pacientes, pelos exemplos dos professores que tiveram ao longo do processo de escolarização e pelas semanas pedagógicas, que ocorriam esporadicamente ou semestralmente nas IES. Mediante tais resultados, conclui-se que é necessária uma ressignificação pessoal, política e social acerca da importância e consequências da formação pedagógica do docente da área da Saúde do Ensino Superior, principalmente, do supervisor de estágio dos cursos de Fisioterapia, para haver a institucionalização do comprometimento com a formação crítica e humanizada dos egressos.

Palavras-chave: Formação docente. Supervisor de estágio de Fisioterapia. Ensino Superior.

\section{Formation, professionalization and teaching identity of the internship supervisor of the Physiotherapy course}

\footnotetext{
1 Mestre em Educação pela Universidade Federal de Rondônia (UNIR), Porto Velho-RO, Brasil. Orcid ID: https://orcid.org/0000-0002-7355-0746. E-mail: 7dalianne@gmail.com.

2 Professora Permanente do Programa de Pós-Graduação em Educação - Mestrado Acadêmico da UNIR, Porto Velho-RO, Brasil. Orcid ID: https://orcid.org/0000-0003-2301-7000. E-mail: brosangela@gmail.com.

3 Professor Permanente do Programa de Pós-Graduação em Educação - Mestrado e Doutorado Acadêmico da UFTM e do Programa de Pós-Graduação em Educação Escolar Mestrado e Doutorado Profissional da UNIR. Coordenador do Departamento de Educação da UFTM, Uberaba - MG, Brasil. Orcid ID: https://orcid.org/0000-0002-8151-0912. E-mail: lucas.bueno@uftm.edu.br.
} 


\section{ABSTRACT}

The contexts of performance of the Health area require professionals with generalist formation, technical-scientific knowledge, ethical posture, humanized practices and with critical-reflexive vision. Based on this premise, this research aimed to analyze the pedagogical formation of the internship supervisor of the Physical Therapy courses, in Porto Velho/RO, and the contributions of this professional to the formation of physiotherapists, also involving aspects related to the teaching identity and professionalization. It is a descriptive-exploratory research of qualitative approach carried out in two private Higher Education Institutions (IES). The results showed that the pedagogical formation for the internship supervision was given by the "selfreflection of the daily practice of the preceptor's office", in the accompaniment of the direct contact of the students with the patients, by the examples of the teachers that they had along the process of schooling and by the pedagogical weeks that occurred sporadically or every six months in the IES. Through these based on the results, it is concluded that a personal, political and social new social significance about the importance and consequences of the teacher's pedagogical formation in the area of Higher Education Health is necessary, especially the supervisor of internship in Physical Therapy courses, in order to have a commitment to the critical and humanized formation of the students.

Keywords: Teacher training. Internship supervisor of Physiotherapy. Higher Education.

\section{Formación, profesionalización e identidad docente del supervisor de} pasantías del curso de Fisioterapia

\section{RESUMEN}

Los contextos en los que opera el área de Salud requieren profesionales con formación generalista, conocimientos técnico-científicos, postura ética, prácticas humanizadas y una visión crítico-reflexiva. Con base en esta premisa, esta investigación tuvo como objetivo analizar la formación pedagógica del supervisor de pasantía de los cursos de Terapia Física, en Porto Velho/RO y las contribuciones de este profesional a la formación de fisioterapeutas, involucrando también aspectos relacionados con la identidad de la enseñanza y la profesionalización. Se trata de una investigación descriptiva-explicativa de enfoque cualitativo, realizada en dos instituciones privadas de enseñanza superior. Los resultados mostraron que la formación pedagógica para la supervisión de las prácticas se daba por la "autorreflexión de la práctica diaria de la oficina del preceptor", en el seguimiento del contacto directo de los estudiantes con los pacientes, por los ejemplos de los profesores que tenían a lo largo del proceso de escolarización y por las semanas pedagógicas que se producían esporádica o semestralmente en las instituciones de enseñanza superior. A través de estos resultados se concluye que es necesaria una resignificación personal, política y social sobre la importancia y consecuencias de la formación pedagógica del docente en el área de Salud de la Educación Superior, principalmente, el supervisor de las prácticas en los cursos de Terapia Física, para tener la institucionalización del compromiso con la formación crítica y humanizada de los egresados. 
Palabras clave: Formación de profesores. Supervisor de prácticas de Fisioterapia. Educación terciaria.

\section{Introdução}

Historicamente, o cuidado com a formação do profissional da área de Saúde sempre esteve presente. O aprendizado na área de Saúde, antigamente, se dava por profissionais experientes e, a partir desta relação de mestre-discípulo, era construído o ensino (MATTOS, 1997).

Atualmente, devido à importância do supervisor de estágio para a formação do aluno da área de Saúde, o processo de ensino-aprendizagem não deve ser realizado por leigos pedagógicos, a partir da experiência profissional de fisioterapeuta somente, por exemplo. Exige-se preparo para que se exerça a função de ensino de modo planejado, consciente, com técnicas, métodos e recursos didáticos, para que a aprendizagem aconteça e o processo de formação realmente se efetive (SILVEIRA, AFONSO, 2012, p. 99).

Tomando como referência esta breve contextualização, este trabalho foi produzido a partir de uma pesquisa acerca da formação pedagógica do supervisor de estágio dos cursos de Fisioterapia, em Porto Velho/RO e teve como objetivo investigar a formação pedagógica, a identidade docente e a profissionalização do supervisor de estágio dos cursos de Fisioterapia em Porto Velho-RO e as contribuições para a formação profissional do fisioterapeuta.

Para concretizarmos o objetivo aqui estabelecido este trabalho teve duas fases: uma teórica e outra empírica. No âmbito teórico, partimos de um estudo bibliográfico e da legislação que ampara a Área da Saúde, a área de Fisioterapia e o Estágio supervisionado em Fisioterapia, promovendo uma interlocução sobre a formação docente na área de Saúde, sua relação com a identidade e a profissionalização docente e as consequências para a formação dos egressos. No âmbito empírico, a pesquisa ocorreu em Rondônia, na cidade de Porto Velho, Região Norte do Brasil, que possui três faculdades privadas de Fisioterapia. Das três faculdades, optamos em delimitar nosso campo de investigação a duas, pois a terceira, no período da pesquisa, não possuía turma concluída ou em formação no estágio 
supervisionado, de forma que não havia o campo e os possíveis participantes da pesquisa para serem investigados. Portanto, os participantes da pesquisa foram os supervisores de estágio de Fisioterapia de duas Instituições de Ensino Superior (IES) de Porto Velho/RO.

Ao procedermos à análise dos dados, estes nos permitiram fazer inferências que ponderam que a formação docente é necessária à profissionalização e à identidade docente do supervisor de estágio do curso de Fisioterapia. A formação, para ter efeito, não deve ser feita sozinha, ou exclusivamente em semanas pedagógicas de início de semestres, ou por políticas isoladas das IES. É necessária a conscientização e a ressignificação da formação de professores, do papel das IES e do Estado, que deve regular, supervisionar e cobrar a formação continuada.

Compreendemos que seja a partir da constituição da identidade do professor do Ensino Superior e das funções exercidas nas IES que deverão ser estabelecidos os parâmetros e as ações da formação inicial e continuada dos professores deste nível de atuação docente.

Na busca de uma melhor compreensão do nosso objeto de estudo, o desenho deste texto se materializou por meio de uma estrutura organizada em três sessões que abordam a formação docente para o Ensino Superior, a identidade e a profissionalização e a formação docente para o Ensino Superior na Área da saúde e na Supervisão de estágio do curso de Fisioterapia.

Como todo trabalho científico deve apresentar, de alguma forma uma relevância, entendemos que a principal contribuição do presente trabalho seja a crítica elaborada sobre a formação pedagógica do supervisor de estágio do curso de Fisioterapia, para a formação do futuro profissional fisioterapeuta, evidenciando que, considerando as mudanças de paradigmas do ensino na área de Saúde, o professor que ainda transmite conhecimentos fragmentados e descontextualizados das necessidades sociais não consegue sozinho superar as formas tradicionais de ensino, por isso, a formação do professor voltada às questões didático-pedagógicas se faz fundamental para formação do futuro profissional da área de Fisioterapia, 
frente às necessidades sociais e às exigências do Sistema Único de Saúde (SUS) e do Ministério da Educação.

\section{A formação docente para o ensino superior}

A identidade profissional dos professores do Ensino Superior não é definida da forma que é para os professores da educação básica, sendo motivo de vários estudos e pesquisas do meio acadêmico, para suscitar as questões e consequências para a indefinição da identidade profissional ou para propor possíveis delineamentos laborais, subjetivos e objetivos para a profissionalização (BRZEZINSKI, 2002); (ZABALZA, 2007); (PIMENTA; ANASTASIOU, 2010), (VEIGA, 2011) e (MASETTO, 2012).

Podemos compreender que a identidade do professor do ensino superior sofre geralmente uma dicotomia na relação profissão técnica e docente, como se fosse possível conceber a separação entre os saberes específicos e os saberes pedagógicos na construção da identidade e da profissionalização docente. Assim, o profissional passa a receber valorização na profissão técnica e não na profissão docente, relegando a última para o desenvolvimento individual ou como uma atividade laboral alternativa e incerta de remuneração, para a maioria dos profissionais docentes do ensino superior.

Dessa forma, mesmo ouvindo alguns professores do ensino superior dizerem que a profissão que exercem é a de "professor do ensino superior", a identidade profissional docente ainda é considerada secundária, difusa e costuma estar centralizada em conhecimentos específicos e não nas especificidades epistemológicas e pedagógicas da docência (ZABALZA, 2007).

Zabalza (2007) afirma que tal situação, que podemos chamar de distopia formativa, advém do fato de ser comum que docentes se especializem e realizem a formação continuada em área de conhecimentos técnicos específicos, deixando de lado os conhecimentos da dimensão pedagógica e da educação. 
Um dos aspectos mais críticos dos professores (em todos os níveis do sistema de educação) tem sido justamente o de ter uma identidade profissional indefinida. Sua preparação para a prática profissional esteve sempre orientada para o domínio científico e/ou para o exercício de atividades profissionais vinculadas a ele. Com estes precedentes é difícil, a princípio, construir uma identidade profissional vinculada à docência (ZABALZA, 2007, p. 107).

Da mesma forma, Pimenta e Anastasiou (2010) afirmam que, geralmente, quando o professor é convidado a ingressar na docência do ensino superior é porque indicou que possui bom embasamento teóricocientífico nas áreas de atuação profissional; porém, o conhecimento do processo ensino-aprendizagem se desenvolve, a posteriori, na própria prática docente.

Por isso, há diversas críticas e discussões no meio acadêmico, quanto ao "ser profissional docente do ensino superior", pois o que diferencia o docente de outros profissionais, segundo Larsson, Talbert e McLauglin (1977, 1994 apud DAY, 2001, p. 21, grifo nosso) são:

i) um conhecimento-base especializado - cultura técnica;

ii) o compromisso de satisfazer as necessidades dos clientes - ética em serviço;

iii) uma forte identidade coletiva - compromisso profissional;

iv) controle colegial, em oposição ao controle burocrático, sobre as práticas e padrões profissionais - autonomia profissional.

Por essas diferenças entre os profissionais docentes e outros podemos inferir que a identidade docente é estabelecida de forma a singularizar uma categoria profissional, estabelecendo uma cultura formativa científica, ética, profissional, organizacional e autodeterminativa.

Entretanto, para Brzezinski (2002), há uma efetiva inércia de influência do Estado na regulamentação do ingresso e do trabalho docente nas instituições de ensino superior, que desestimula a profissionalização docente, porque, desde a seleção para o exercício da docência, não há oferta de formação qualificada em serviço, de forma que a formação continuada é relegada para a responsabilidade do professor, que deve desenvolver a própria formação continuada, sem um plano institucional que construa o 
pertencimento, a identidade e a profissionalização para docência, balizando que:

[...] pela perversidade do sistema capitalista, a ação governamental degradadora da profissão docente vem traindo sucessivamente os discursos encontrados nos planos do governo. Estes enfatizam a relevância da política educacional voltada para a capacitação de novos contingentes de profissionais, situando a educação na linha de ataque, por constituir poderosa arma de serviço do desenvolvimento, do progresso social e da expansão do emprego. Com efeito, atualmente, os profissionais da educação se aproximam da proletarização. Secundarizada ou proletarizada, a profissão docente reveste-se de total falta de profissionalismo (BRZEZINSKI, 2002, p. 13).

Assim, podemos inferir que a profissionalização docente se conceitua como o oposto de desempenho leigo, amador, sem cientificidade, baseado somente na experiência. Da forma que está posta a atuação do profissional docente, a priori, como uma prática, a autora, define a concepção do que seja a profissionalização docente.

Masetto (2012) compreende e destaca que o docente do ensino superior deve ser competente em uma área específica e que a competência deve advir da pesquisa, além de necessitar dos conhecimentos pedagógicos da disciplina, para alcançar o profissionalismo docente e afirma que:

Dificilmente se pode falar de profissionais do processo ensinoaprendizagem que não dominem, no mínimo, alguns grandes eixos desse processo: o próprio conceito do processo ensino-aprendizagem, a concepção e gestão de currículo, a integração das disciplinas como componentes curriculares, a compreensão da relação alunoprofessor e aluno-aluno, a teoria e a prática da tecnologia educacional, a concepção do processo avaliativo e suas técnicas para feedback, o planejamento como atividade educacional e política (MASETTO, 2012, p.32).

Para Zabalza (2007), o profissional docente pode ser definido e analisado por três dimensões: a dimensão profissional (que diz respeito à identidade profissional, que são as autoexigências); a dimensão pessoal (que diz respeito às motivações pessoais para o exercício da docência, os compromissos pessoais com a docência) e a dimensão institucional (que se 
refere às condições contratuais e investimento no docente). Essas dimensões se tornam indissociáveis para a profissionalização docente.

Para complementarmos o pensamento de Zabalza (2007) sobre a dimensão profissional do docente, buscamos compreender a partir de Pimenta e Anastasiou (2010), para quem a identidade docente é construída por quatro saberes, os quais se direcionam ao ensinar docente, auxiliando-o a rever e criar práticas, de forma que:

[...] nos processos de formação de professores é preciso considerar a importância dos saberes das áreas de conhecimento (ninguém ensina o que não sabe), dos saberes pedagógicos (pois o ensinar é uma prática educativa que tem diferentes e diversas direções de sentido na formação do humano), dos saberes didáticos (que tratam da articulação da teoria da educação e da teoria de ensino para ensinar nas situações contextualizadas), dos saberes da experiência do sujeito do professor (que dizem do modo como nos apropriamos do ser professor em nossa vida) (PIMENTA; ANASTASIOU, 2010, p. 71).

Para Formosinho (2009), os saberes da experiência do professor são valorizados no meio acadêmico, pois a formação de professores possui determinadas especificidades da formação de outros profissionais. Na maioria dos casos a docência é uma profissão que se aprende observando os professores na faculdade, de forma direta e indireta no decorrer do curso.

[...] a docência é uma profissão que se aprende desde que se entra na escola, pela observação do comportamento dos nossos professores. Não acontece isso com outras profissões. O professor utiliza, para transmitir o saber profissional, o seu próprio saber profissional. Isto é, um professor de ensino ao ensinar, transmite inevitavelmente conhecimentos e atitudes sobre esse processo de ensino, pelo que diz e pelo que faz [...] (FORMOSINHO, 2009, p. 95).

Por essa perspectiva o fato de o futuro professor assistir a diferentes aulas e ser solicitado para apresentar trabalho, por exemplo, faz parte do aprendizado por experiência, constituindo uma parte fundamental para a formação prática do docente, podendo até inferir que o aprendizado prático docente é construído nas experiências vividas ao longo da escola, de modo artesanal (FORMOSINHO, 2009). 
Para o professor de cursos bacharelados, equivocadamente, podemos encontrar justificativas acerca de que o saber estabelecido pela experiência, que se constitui na observação de outros profissionais em serviço, seja o suficiente para suprir a falta de formação continuada docente. Entretanto, como discorrido anteriormente, somente as experiências observadas não bastam para a construção da identidade e profissionalização do professor do Ensino Superior.

Nesse contexto, Zabalza (2007), Formosinho (2009), Pimenta e Anastasiou (2010), Masetto (2012) convergem para a compreensão que as mudanças nas demandas do meio produtivo levaram à necessidade de reconstrução educacional e, assim, o professor e as IES se encontram inseridos em processos de transformações que afetam as demandas e as ofertas educacionais e, por conseguinte, a formação e a profissionalização docente.

As questões sobre a formação docente são agravadas nos cursos da área de Saúde, já que, além de os alunos não contarem com disciplinas didático-pedagógicas na matriz curricular, ainda há disciplinas de formação humanística (filosofia, sociologia, antropologia, psicologia, ética, etc.) com carga horária reduzida, acelerada ou suprimida, configurando a formação do profissional da área de Saúde desvinculada e precarizada frente às questões humano-sociais do ambiente em que irão atuar e que definirão a formarão dos profissionais em serviço, conforme será tratado, a seguir.

\section{A formação, identidade e profissionalização docente na área de saúde: um olhar sobre a formação do supervisor de estágio do curso de Fisioterapia}

Na área de Saúde a formação de professores vem encontrando espaços de discussão para construir a identidade profissional do professor e desenvolver a formação pedagógica dos profissionais que atuam neste campo do saber, a partir de eventos que promovem a exposição coletiva, conforme destacam Pimenta e Anastasiou (2010). Inclusive, enfatizamos que, segundo Brant (2011), pesquisas sobre a formação de professores estão transpondo os espaços dos cursos de formação de professores - espaços até então restritos à área de Educação e alcançando outras áreas: 
No Congresso Brasileiro de Educação Médica, o mais importante evento sobre educação médica do país, a preceptoria, a capacitação do preceptor e as suas correspondentes tarefas e responsabilidades na formação médica são motivo de discussão e de apresentação de trabalhos, que corresponderam a quase $5 \%$ dos estudos no ano de 2007, a 10\% em 2008, e a $6 \%$ em 2009, dentre todos os que foram apresentados por instituições de ensino de dezenove estados brasileiros (BRANT, 2011, p.7).

Assim, o docente que atua na área de Saúde vem se envolvendo nas questões educacionais, além daquelas referentes à assistência ao ser humano e às demandas de saúde da própria comunidade, emergindo a necessidade de aprofundamento didático-pedagógico e de exercitar a criticada reflexão na ação, em ambientes de atuação prática, para melhor formar os futuros profissionais.

A formação do profissional da área da Saúde passa pelo desafio de "romper paradigmas que a colocam na direção de uma formação com pertinência social e coerência com as Diretrizes Curriculares Nacionais (DCN)" (BRASIL, 2006b, P. 31).

Determinados princípios doutrinários e organizacionais da formação docente para a área de Saúde emergiram do Sistema Único de Saúde (SUS) e da Constituição Federal de 1988, sendo eles: acesso igualitário e universal a ações e serviços; participação comunitária; regionalização de rede/hierarquização; e descentralização, cujas ações de saúde devem ser desenvolvidas de acordo com as diretrizes previstas no Art. 198 da Constituição Federal, obedecendo ainda princípios como: (i) universalidade de acesso aos serviços de saúde; (ii) integralidade de assistência, constituindo um conjunto contínuo e articulado das ações e serviços para a promoção da saúde, individuais e coletivos, exigidos para cada caso em todos os níveis de complexidade do sistema; (iii) igualdade da assistência à saúde, sem preconceitos ou privilégios de qualquer espécie.

Não obstante, a Constituição Federal de 1988 assegura ao SUS a organização e integração do processo de ensino-aprendizagem dos graduados na área de Saúde, porém Campos et al. (2001) avaliam que tal 
preceito constitucional não se aplica à prática institucional e que o fato de o mercado de trabalho do profissional da saúde, no sistema público, ser amplo e rentável, não parece gerar mudanças no ensino para os futuros profissionais da área. Neste contexto, afirmam que:

A desarticulação entre as definições políticas dos Ministérios da Saúde e da Educação têm contribuído para acentuar o distanciamento entre a formação dos profissionais e as necessidades do SUS" (CAMPOS et al., 2001, p.54).

Desta forma, o Ministério da Saúde e o da Educação afirmam que o modelo Universitário, com autonomia nas decisões, fez com que ocorresse um afastamento das reais necessidades do processo saúde-doença da população brasileira, de forma que,

\begin{abstract}
Mesmo as transformações concretas da modelagem assistencial, que caminha em todo o mundo na direção de um modelo mais holístico e promotor da saúde encontra retardo para penetrar nas instituições de ensino. Ali, a reprodução de modelos de práticas pretéritas muitas vezes ainda prevalece. Superar um modelo biologicista, unicausal e centrado exclusivamente no biológico é um grande desafio hodierno (BRASIL, 2006b, p. 7).
\end{abstract}

Assim, o Ministério da Saúde e o Ministério da Educação buscam implementar estratégias de ensino que tragam integração da Educação com a Saúde, visando a melhoria do bem-estar do cidadão. A LDB/96, em seu Art. $43, \S$ I, prevê que as IES estimulem o espírito científico e o pensamento reflexivo dos alunos. As Diretrizes Curriculares Nacionais (DCN), apresentadas no Parecer CNE/CES 1.133/2001, auxiliam na construção do projeto pedagógico dos cursos (PPC) e nas características da formação a ser oferecida aos estudantes da Saúde e buscam a integração da área de Saúde com a Educação (Brasil, 2006).

No documento está previsto,

O perfil do profissional de saúde definido nas diretrizes é de um indivíduo com formação generalista, técnica, científica e humanista, com capacidade crítica e reflexiva, preparado para atuar, pautado por princípios éticos, no processo de saúde-doença em seus diferentes níveis de atenção. Enfatiza-se a perspectiva da integralidade da 
assistência, com senso de responsabilidade social e compromisso com a cidadania (BRASIL, 2006, p. 13).

Em Brasil (2006) está enfatizado que o processo de ensino focado no aluno deve prevalecer, ao propor que, na relação entre ensino e aprendizagem, o centro deve ser o estudante. E o professor deve ser $\mathrm{O}$ facilitador e mediador do processo, baseando-se na aprendizagem ativa. A inserção do aluno nos primeiros anos de formação ao sistema público de saúde constitui o aprendizado baseado em soluções de problemas, evidência e competência.

Diante das exigências do Ministério da Educação e do Ministério da Saúde, o modelo de ensino, em que o professor é o detentor do conhecimento, não deveria ser aplicado à educação do Ensino Superior, especificamente na área de Saúde, como também nas demais áreas do conhecimento.

Segundo Perrenoud et.al (2007), os cursos de Medicina, bem como os cursos da área de Saúde como um todo, passaram por um processo de transformação, considerando que antigamente os estudantes aprendiam toda a teoria para depois fazerem a associação prática nos estágios, que ocorriam nos últimos anos do curso. Para ele, é necessário, por exemplo, que nestes currículos esteja previsto que o aluno já tenha discussão de casos clínicos desde o princípio do curso, ao esclarecer que:

A aprendizagem por problemas induz a outro tipo de currículo totalmente diferente; desde o início, os estudantes são confrontados com casos clínicos: primeiramente, simples e no papel e, posteriormente, mais complexos e relativos a casos reais. Diante desses problemas, eles tomam consciência dos seus recursos metodológicos e teóricos, e isso faz com que surja a necessidade de formação. A partir daí, eles podem retomar o problema a ser resolvido com mais recursos (PERRENOUD et.al, 2007, p. 21).

A dicotomia de teoria e prática realizada por professores de disciplinas teóricas e por professores de estágio deveria ser desfeita, pois inibe o aprendizado, a identidade profissional dos alunos, a reflexão e a crítica. Geralmente, ao professor de disciplinas teóricas fica o aprendizado teórico 
sem se preocupar com as realidades da profissão e no estágio fica a responsabilidade para o professor posicionar os alunos sobre as demandas da profissão. Os professores deveriam se sentir responsáveis pelo aprendizado teórico-prático e contribuírem na construção de saberes, sem a dicotomia comumente praticada (PERRENOUD et. al, 2007).

Considerando a dicotomia teoria e prática, Franco (2011) expõe que é necessário rever as concepções docentes quanto à prática pedagógica, pois:

[...] a prática docente é sempre mais que visível das ações técnicas de um professor frente à sala de aula. Considero que o sentido de prática docente precisa ser rediscutido de forma superar a concepção arraigada de prática docente como o desempenho de determinadas ações considerados previamente necessárias a um determinado tipo de aula. [...] A atividade prática docente não se circunscreve no visível da prática pedagógica em sala de aula. A prática, não se realiza, apenas nos procedimentos didáticos metodológicos utilizados pelo professor. A prática docente é um trabalho docente que se organiza em vários tempos e espaços (FRANCO, 2011, p. 163).

Do mesmo modo, Libâneo (2011) aponta o problema da falta de conhecimento e a negação do conhecimento pedagógico dos docentes do ensino superior, ao destacar que há dois problemas no ensino universitário que são reincidentes, sendo:

a) o desconhecimento ou a recusa das contribuições da pedagogia e da didática; b) a separação entre o conteúdo da disciplina que se ensina e a epistemologia e métodos investigativos dessa disciplina. Muitos professores ainda se utilizam da didática tradicional, que se ocupa meramente dos aspectos prescritivos e instrumentais do ensino. Outros, não ajudam os alunos a vincular sua aprendizagem ao domínio dos procedimentos lógicos e investigativos da disciplina ensinada (LIBÂNEO, 2011, p. 191).

A formação técnica e pedagógica do docente na área de Saúde deve contribuir para a formação do futuro profissional graduado. Do professor da área de Saúde, especificamente do supervisor de estágio, são exigidos competência e conhecimento teórico-científico para atender demandas do próprio paciente e da família, além de conhecimentos didático- 
pedagógicos, para desenvolver no aluno a capacidade crítica, frente aos problemas que poderão surgir durante a formação.

$\mathrm{Na}$ Fisioterapia o estágio supervisionado é o momento régio da aprendizagem profissional e da construção da identidade do fisioterapeuta. É quando o aluno tem a oportunidade de questionar de maneira crítica o que foi aprendido na prática, confrontar a teoria e refletir coletivamente sobre as características próprias do fisioterapeuta e sobre as realidades sociais da saúde e das instituições de saúde.

O conceito de estágio supervisionado, definido na Lei 11.788, de 25 de setembro de 2008, em seu Artigo $1^{\circ}$, define:

Estágio é ato educativo escolar supervisionado, desenvolvido no ambiente de trabalho, que visa à preparação para o trabalho produtivo de educandos que estejam frequentando o ensino regular em instituições de educação superior, de educação profissional, de ensino médio, da educação especial e dos anos finais do ensino fundamental, na modalidade profissional da educação de jovens e adultos.

A partir da Lei 11.788 ficou definido nos incisos I e II do Art. $1^{\circ}$, que o estágio supervisionado deve fazer parte do projeto pedagógico do curso e que o aluno deverá ser formado para competências da atividade profissional, voltado para o trabalho e para a atividade cidadã (BRASIL, 2008).

Desta forma, o estágio supervisionado deve se constituir parte integrante do currículo do curso, respeitando as características culturais, sociais e regionais. Além de que o estágio supervisionado deve instigar reflexões sobre o campo, no qual o futuro profissional irá atuar e não somente ser considerado como uma simples parte prática do curso. Os CNE/CES, com os Pareceres 776/97 e 67/2003, trazem como um dos princípios das DCN dos Cursos de Graduação o de:

[...] fortalecer a articulação da teoria com a prática, valorizando a pesquisa individual e coletiva, assim como os estágios e a participação em atividades de extensão, as quais poderão ser incluídas como parte da carga horária [...]. 
Assim, podemos inferir que o estágio supervisionado em Fisioterapia integra a formação profissional do aluno, a partir da ação prática de atenção à sociedade, procurando a formação ética, generalista e crítica, preocupada com as transformações sociais, respeitando as diretrizes e os princípios do SUS. A formação se dá a partir da interação do aluno com o supervisor de estágio, como já exposto, sob a responsabilidade da IES.

Por isso, a postura ética do aluno perante o paciente que está sendo atendido é analisada e avaliada no estágio, pois, a forma como o terapeuta faz uso das técnicas de tratamento e aborda o paciente, interferem no processo de cura, completando de forma positiva o tratamento do paciente. Suda, Uemura e Velasco $(2009$, p.130) afirmam que as atitudes de valorização do paciente como pessoa humana devem fazer parte da formação em saúde, de forma que:

O acadêmico de Fisioterapia, desde sua entrada no curso superior, deve compreender os princípios de ética profissional, buscando padrões de qualidade de forma crítica e reflexiva. A evolução e progressão dos módulos vinculando prática e teoria, em uma rotina de observação, culminando com os estágios supervisionados nos últimos semestres, amplia valores nos alunos, como o respeito pelo paciente, a quebra de preconceitos socioeconômicos e a necessidade do trabalho em equipe.

O aluno se depara com as dificuldades e se vê na necessidade de aprimorar e refletir sobre propostas de tratamentos. Também tem a oportunidade de ter o contato com os pacientes e vivenciar junto as mazelas sociais e do serviço público de saúde, criando a conduta de tratamento fisioterapêutico, de assumir o compromisso ético e crítico com as famílias dos pacientes e com a sociedade, a partir do que é sugerido pelo supervisor de estágio. Nesta inquietação podem surgir, a partir de instigações do supervisor de estágio, as iniciações às pesquisas científicas, que auxiliam na construção da identidade do profissional fisioterapeuta.

Do mesmo modo, entre tantos desafios que o aluno poderá encontrar no estágio supervisionado e na formação da identidade profissional, a relação entre estagiário e supervisor fica aparente. Relação em que o 
supervisor de estágio passa a ser o exemplo de profissional para o estagiário, ou a negação com perspectivas de caminhos diferentes a percorrer, emergindo a necessidade dos supervisores de estágio atuarem com postura profissional adequada, mas além de tudo, com formação pedagógica para atender o que a legislação e o SUS preconizam e determinam para o futuro profissional.

Desta maneira podemos inferir que os avanços alcançados historicamente tanto na profissão de fisioterapia, nas percepções do processo saúde/doença pela sociedade e pelo profissional, quanto nas mudanças curriculares do curso, constituíram peças fundamentais no processo ensinoaprendizagem do aluno e na formação do professor/supervisor de estágio.

Partindo do princípio que a profissionalização e a reflexão crítica da prática docente podem subsidiar a construção da identidade do professor supervisor de estágio da Fisioterapia, ainda há diversos outros fatores que necessitam ser repensados, por também estarem envolvidos, como o projeto pedagógico do curso, a matriz curricular e a mudança na avaliação do processo de ensino-aprendizagem dos alunos, que requer professores capacitados, que instigam o aluno a participar ativamente na construção do conhecimento de forma holística, enquanto concepção de saúde, de forma crítica e coletiva e enquanto concepção social, atendendo às demandas dos princípios e das diretrizes do SUS.

\section{Resultados e discussões}

Os conceitos e as reflexões que foram construídas a partir da seção de referencial teórico intercomunicam com a análise dos dados, com o propósito de responder ao objetivo da pesquisa. A análise, interpretação e discussão dos resultados obtidos na entrevista com os participantes do presente estudo estão apresentadas a seguir.

Para preservar a identidade dos participantes da pesquisa, utilizamos a sigla "SE", significando "Supervisor de Estágio" e, em seguida, a numeração, utilizada para nossa identificação dos participantes. 
À luz do referencial teórico, consideramos que a formação inicial e continuada do supervisor de estágio constitui peça fundamental para a construção da identidade e profissionalização do futuro profissional. Neste sentido, apresentamos algumas falas dos participantes do presente estudo para análise:

\begin{abstract}
Quando você está em processo de formação, você adquire alguns conhecimentos dos professores. Mas, esta influência foi por certo tempo, pois cada professor vai construindo sua identidade, sua melhor forma de avaliação. Então, a observação influenciou no primeiro momento, hoje não [...] (SE1).

[...] Acho que é tão importante nos lembrarmos de quando éramos alunos, frente ao que foi explicado e você não conseguiu entender e de que forma você gostaria que isto tivesse sido explicado para você. Então, isto de certa forma, contribuiu muito para eu chegar mais perto do aluno, entender qual foi sua dificuldade no estágio (SE6).

Nós precisamos de exemplos para dar nossos passos iniciais, sem estes exemplos ficaria praticamente impossível atuar como supervisor de estágio. Os melhores exemplos, as melhores didáticas, que trazemos para a gente e levamos à diante (SE10).

[...] Os professores eram bem rigorosos no aprendizado, cobravam bastante, não cobravam somente a teoria, porque acho que o aluno tem que saber aplicar a prática e se expressar. Trago muito isso comigo. Espelhei com vários professores que tinham esta linha, que buscavam não só a teoria, como a prática. Tentavam unir de toda forma a teoria e prática e não davam só valor na nota final e sim no aprendizado final, tanto da prática, como da teoria (SE14).
\end{abstract}

Os supervisores de estágio consideram que o exemplo e a postura dos professores de graduação possam ter influenciado inicialmente como docente e na supervisão de estágio. Exemplos de como avaliar o aluno, de didática no estágio, que contribuíram inicialmente, mas depois procuraram traçar a própria identidade profissional, encontram a seguir.

Como me dediquei muito ao curso e levei muito a sério a faculdade, sempre observei de forma crítica os professores e analisava o que dava certo, a forma que eles atuavam, o método de ensino e as avaliações. A forma que os supervisores agiam no campo influenciava muito o aluno. Os exemplos que me eram passados eram absorvidos por mim. Alguns professores reconheciam suas dificuldades profissionais e de infraestrutura do local de estágio, deixando isto claro para os alunos, outros não faziam isto. Observava também as abordagens técnicas (SE2).

Meus professores davam um jeito de nos fazer pensar e isso peguei um pouco com meus professores. E a questão também de ser ético, respeitar os colegas, saber trabalhar com qualquer tipo de pessoa. Às

Revista Exitus, Santarém/PA, Vol. 10, p. 01-29, e020094, 2020. 
vezes converso com estes meus ex-professores e agradeço, digo que ainda bem que eles foram assim comigo. Agora estou sendo assim com meus alunos, mas sempre tento me aperfeiçoar (SE5).

Principalmente, a escuta acolhedora, o fato de parar e escutar tanto o paciente, quanto o aluno; de tentar trazer para o aluno a visão do conjunto; não que ele olhe o paciente como um só, mas fazer com que o aluno não se constranja diante dos pacientes e dos colegas. E, principalmente, trazer o senso de responsabilidade, pelo compromisso de estar ali. Isso acabei aprendendo com os docentes que observava em minha graduação (SE3).

Os participantes da pesquisa relatam que receberam influências na formação docente e na prática do estágio supervisionado, ao observarem a postura ética dos professores, a responsabilidade e o compromisso com o trabalho e a atividade que estavam exercendo. Salientam que, por exemplo, a exposição dos professores sobre as limitações que possuíam em relação a conhecimentos técnicos e de problemas com a infraestrutura do local de estágio, contribuíram de forma positiva na atuação docente. De forma que podemos destaca que:

Uma delas está relacionada com a discussão que eles faziam direcionada a estudos de casos e a avaliação de aluno. É, assim, procuro atuar com meus alunos (SE4).

O professor é uma figura marcante na vida do aluno. Algumas coisas que aprendi antigamente com meus professores, hoje, acabo me lembrando (SE7).

Ela (a observação dos professores da graduação) contribui no sentido de nos espelhar no que os professores têm de melhor, para a gente unir e ser o melhor que posso. Sempre me espelhei nos meus professores e usei da base que tinha para tentar ser o melhor supervisor possível (SE8).

Quando a gente tem um aluno interessado, aquele professor que está disposto a ensinar, se doar para o conhecimento do aluno, é aquilo que a gente leva para a vida... Se o professor "puxa a orelha" e a gente para prá pensar, a gente não esquece nunca mais. [...] Até hoje tento passar para meus alunos exatamente esta confiança de "vamos lá", de pegar na mão, porque sei exatamente quais são os medos, por já ter passado por isso. Esta segurança, os puxões de orelha, que me fizeram crescer e gostar da área que atuo hoje (SE9).

Não tanto só na docência, mas na prática técnica, que de certa forma eles acabaram me influenciando a me tornar professora. Eu não me esqueço deles. Lembro-me do jeito deles de ensinar - a metodologia - mas acho que nem eles tinham a compreensão da docência (SE11).

Podemos analisar que mais da metade do grupo de participantes da pesquisa assumem ter sido influenciada pelos professores de graduação e que 
as influências ficaram marcadas na memória, levando-os a pensar se somente tais influências foram suficientes para as práticas docentes.

Formosinho (2009) afirma que professores de licenciaturas aprendem a ser professores, a partir do momento que entram na escola e começam a observar o comportamento dos professores. Que o professor transmite de forma inevitável o que tem de conhecimento por atitudes, porém, com os professores de bacharelado, a transmissão do saber ocorre no momento prático, confirmando as falas dos supervisores de estágio, expostas anteriormente, sobre as experiências de observação dos professores da formação inicial.

A identidade do docente universitário vai se consolidando no decorrer da graduação, nas oportunidades acadêmicas, observando os docentes, no contato com a teoria e a prática e diretamente pelo estágio das disciplinas (PIMENTA; ANASTASIOU, 2010).

Porém, Pimenta e Anastasiou (2010) ressaltam que somente o saber adquirido pelas experiências não são suficientes para o processo de formação e profissionalização docente. Alegam que há necessidade de aprofundamento nos saberes das áreas de conhecimento, dos saberes pedagógicos e dos didáticos.

Dessa forma, compreendemos que o supervisor de estágio traz consigo diversas experiências e crenças obtidas ao longo da vida, do processo de escolarização e formação profissional, porém não o creditam para exercer com plenitude a docência.

Entretanto, nas falas dos participantes da pesquisa analisamos como foi importante a observação dos professores para a atuação profissional, posto, assim, o imperativo de considerar como concebem ou idealizam a necessidade de formação continuada para a construção da identidade e da profissionalização docente:

[...] Eu acredito que é necessário buscar informações para estar no estágio em que estou supervisionando. Preciso de informações para me manter neste estágio, porque não quero apenas estar aqui 
somente de corpo presente. Quero contribuir para a formação do aluno, ainda que não seja minha área de afinidade [...] (SE1).

[...] A formação continuada técnica contribui muito, pois, a partir do momento que se escolhe a Área da Saúde, é necessária a atualização constante e isto faz com que a gente traga novas experiências para o aluno e exige que ele tenha uma nova visão, para formar opinião. O aluno está muito acostumado a pegar informações da internet, de fontes não confiáveis e informações de livros que já estão obsoletos. Se a gente traz um conteúdo novo e o aluno consegue coincidir as duas opiniões e formar a própria, a nossa missão está cumprida (SE3).

[...] Nosso aperfeiçoamento também melhora o conhecimento do aluno. Quanto mais eu tenho conhecimento, mais conhecimento tenho para passar para o aluno. [...] Faço mais minha formação continuada, voltada para a área técnica. Mas, a faculdade dispõe para a gente de seis em seis meses um curso na área pedagógica (SE8).

Com certeza, porque a formação continuada faz com que nos aperfeiçoamos mais. Então, muitas coisas que aprendemos na faculdade mudam, por exemplo, na parte de cardiorrespiratória e neurologia. O que aprendemos anteriormente, já se atua de outra forma. Este aperfeiçoamento é importante para podermos passar a informação certa para o aluno (SE 14).

Os participantes da pesquisa relatam que realizam formação continuada na área de conhecimento profissional, para se atualizarem e acompanharem as mudanças do processo ensino-aprendizagem ocasionado com o advento da aproximação das tecnologias à educação. Reconhecem que a formação continuada é importante para a formação profissional do aluno, porém não demonstram importância para a formação continuada voltada à área pedagógica.

[...] mesmo depois da formação, e cada vez que você faz um curso diferente, aprende uma técnica diferente, é um professor diferente que te ensina. Daí você acaba aprendendo e observando a forma de ensinar deste professor e pode aplicar com seus estagiários (SE5).

Somente com a formação da graduação ficamos muito limitados, se eu quero cobrar do meu aluno o interesse de estudar e crescer, também tenho que estudar e crescer. Acho que a formação continuada engrandece nossa confiança, nosso conhecimento, para passar para o aluno. Esta formação continuada é mais voltada para a área profissional, mas na área pedagógica não, até porque ser professor nunca foi meu sonho [...] (SE9).

Contribui, pois a formação nunca é perdida, é uma forma de estar em contato com conteúdos diferentes, sempre tem na formação a partilha de experiências e conhecimentos, de vivências positivas de outros estágios. Hoje busco mais formação continuada voltada mais para o lado profissional, menos pedagógico, porém olho na minha 
formação profissional o pedagógico, não tem como desvincular (SE13).

Analisando a fala dos professores, ressaltamos que os supervisores consideram que a formação continuada em área de conhecimento da Saúde contribui para a formação docente, por meio da observação da prática docente dos professores. Consideram que a formação continuada os auxilia na confiança de supervisionar estágio. Porém, observamos na fala do entrevistado SE9 que a opinião sobre ser supervisor de estágio do ensino superior se limita aos conhecimentos da área específica de atuação, deixando transparecer a fragilidade com questões da dimensão pedagógicas e afastando-se da construção da identidade e da profissionalização docente.

[...] a Área da Saúde é muito nova, tudo muda constantemente, assim é preciso estar atualizado e encontrar outras estratégias para alcançar seus objetivos com o aluno. A formação continuada, voltada para a área de educação contribui com o supervisor de estágio no sentido de abrir mais sua visão, pois temos uma formação ultrapassada, baseada em repetição, e hoje não pode ser mais assim, pois desta forma não ocorre o processo de ensino-aprendizagem. Faz diferença em sua abordagem com o aluno e os atendimentos que ocorrem durante o estágio (SE2).

[...] O curso que realizei foi a pós-graduação em metodologia do Ensino Superior e as capacitações pedagógicas que são fornecidas semestralmente pela instituição. Isto contribuiu para minha atuação como supervisor de estágio principalmente no processo de avaliação do aluno (SE4).

[...] a todo o momento a gente precisa estar aprendendo algo a mais, e para você ensinar, você precisa estar o tempo todo estudando. Eu fiz a pós-graduação em Metodologia do Ensino Superior, que é voltado mais para a parte educacional, e uma pós para a área de saúde (SE7).

Não tenho dúvida disto, acho e acredito que tínhamos que ter uma vez por mês que seja, aulas de educação continuada, mas não só com fisioterapeuta, mas a parte de formação pedagógica. [...] Tenho uma amiga que sempre dizia que nós não somos professores, nós somos fisioterapeutas, agente chega para dar aula e às vezes não temos norte, e temos a sorte de saber dar aula. Que muitos fisioterapeutas não têm esta facilidade. Pense para um fisioterapeuta que está acostumado a trabalhar com fichas de avaliação pegar um plano de ensino e fazer... Coisas que são extremamente pedagógicas... (SE12). 
Constatamos que determinados supervisores de estágio reconhecem a importância da formação continuada voltada à área pedagógica, mesmo que a formação seja realizada por capacitações pedagógicas oferecidas pela instituição, no início dos semestres letivos. As contribuições formativas institucionais estão relacionadas à avaliação do aluno de estágio, à facilitação do processo ensino-aprendizagem e à prática docente de modo geral.

É muito importante o professor aprender a ser professor. Em conversa com alguns alunos, eu não fui preparado para ser professor, fui convidado para ser professor e assim aceitei. Então, apresentei muitas dificuldades no início, porque não fui preparado para ser professor, não procurei me especializar nisso. Mas conforme foi passando o tempo, junto com a coordenação do curso e a própria instituição que oferecia alguns cursos na semana pedagógica, e pela própria experiência de alguns colegas de trabalho, fui me preparando para ser docente. Hoje, os alunos me passam o feedback da melhora de quando eu entrei na instituição para como estou hoje [...] (SE5).

É impossível o docente e muito mais o supervisor de estágio, hoje não ter formação continuada, principalmente porque sentimos muita necessidade. Hoje em dia, para avaliar o aluno as metodologias utilizadas são diferenciadas, em função das mudanças políticas e pedagógicas. Chega um momento em que aquele professor que não tem formação continuada vai "patinar no mesmo lugar". Ele não evolui e de certa forma atrapalha a formação do aluno, porque mudanças estão acontecendo a todo o momento. Essas mudanças estão relacionadas à formação do aluno, no direcionamento do ensino, das técnicas e das abordagens. Não é possível que eu monte uma aula em 2006 e continue ensinando aquela aula até hoje. É preciso mudar, com apoio científico e melhores argumentações. Hoje em dia temos alunos críticos que questionam a fundamentação teórica do aprendizado (SE11).

[...] Acho que temos que ter formação continuada com profissionais de fora e trazer as experiências para termos um meio de comparação. Temos que ter uma formação continuada também no núcleo em que trabalhamos, para repensar o que estamos fazendo. De certa forma, para se repensar o que se está fazendo, porque o grupo pode interagir, ele pode repensar algumas práticas. Mas, para isso, tem que ter certo amadurecimento do grupo, certa liberdade de expressão, de pensar, de analisar, porque fazemos muito informalmente, em uma hora do café, para interagir. Acharia interessante ter uma forma mais oficializada em relação a isso. Porque se fica trocando de técnicas, é importante construímos nossas próprias diretrizes do curso [...] (SE6).

Com a fala dos dois supervisores transcrita acima, observamos que, mesmo sendo a minoria, proporcionaram contribuições ao nosso estudo. Não podemos pensar em supervisão pedagógica sem formação continuada. A 
formação continuada deveria ter o comprometimento do grupo de colegas de trabalho de maneira mais intensa.

Os supervisores de estágio, ao serem questionados sobre a importância da formação pedagógica para a formação do profissional fisioterapeuta, responderam que:

Já tive uma experiência, pois realizei uma pós em Metodologia do Ensino Superior e meu trabalho de conclusão foi voltado para o currículo. Então, sei da importância de pelo menos o que seria 0 currículo mínimo para trabalhar as habilidades e competências do aluno. Se você não entende, pelo menos o currículo mínimo do curso, fica difícil abordar as competências do fisioterapeuta (SE4).

A formação pedagógica, em minha opinião, ajuda como lidar com o aluno e como o abordar para contribuir com seu aprendizado. 0 estudo pedagógico nos traz vários métodos que vão nos ajudar para que este aluno aprenda de forma mais fácil (SE8).

[...] A formação pedagógica é primordial para o aprendizado do aluno, para o profissional que ele vai se tornar. Tentamos estar sempre passando as informações e nos atualizando também (SE14).

Eu acho muito importante, pois nem todo bom profissional será bom professor. Então, pegar um profissional que seja bem formado tecnicamente e melhorar a formação pedagógica, a capacidade dele estar à frente de uma supervisão de estágio, em sala de aula, por exemplo, com certeza fará a diferença (SE2).

[...] Seria importante desenvolver a reflexão crítica no aluno para ele não ver a fisioterapia não só como a reabilitação e se ver como reabilitação, que ele seja capaz de formar a própria opinião. Estamos formando alunos com opinião pronta e incapazes de selecionar. Isso tem me preocupado bastante. Isso se dá por comodismo do aluno, por ter vindo de uma formação de $1^{\circ}$ e $2^{\circ}$ graus em que ele acata toda a informação ofertada a ele [...] (SE3).

Eu acho que a formação pedagógica contribui imensamente no processo de elaboração em como é, de que forma e em que momento você vai dar tal informação para o aluno, para fazer com que o aluno comece a fazer uma análise, uma reflexão que impacte na sua formação profissional. É aí que percebo que os alunos vêm com alguns vícios, mas desde a formação básica. Às vezes olho para estes alunos e digo que não estou vendo mais vocês como acadêmico, mas sim como futuros colegas de profissão. É desta forma que eu quero me relacionar, se tiver que errar, prefiro que erre na minha frente, para podermos discutir sobre aquilo [...] (SE6).

Assim, mesmo que parte dos supervisores assuma que não realiza formação continuada voltada a área pedagógica, os supervisores reconhecem a necessidade de realizá-la, para facilitar o processo ensinoaprendizagem, para desenvolver a reflexão crítica do aluno e para a construção da identidade docente. 
Destacamos anteriormente, em nosso referencial teórico, que a profissionalização do professor que atua em universidades vem sendo discutida e é reconhecida no meio acadêmico como imprescindível. Como consequência, várias formas de formação continuada estão sendo aplicadas e investigadas nas últimas décadas. Na tentativa de suprir as necessidades da formação docente, as pós-graduações incluíram nas matrizes curriculares a disciplina "Metodologia do Ensino Superior". Mas, a disciplina sempre foi criticada, pois a carga horária era resumida a 60 horas e nem sempre os professores que a ministravam eram da área de Didática. Porém ela, para a maioria dos docentes, vem sendo a alternativa institucionalizada formalmente para a aproximação à formação docente, de reflexão sobre a identidade profissional e a prática profissional (PIMENTA; ANASTASIOU, 2010).

Assim posto, temos a ressaltar que a formação de professores do ensino superior no Brasil se dá, comumente, por meio da formação continuada em serviço, decorrente do comprometimento da instituição e do grupo de docentes, na busca pela identificação do trabalho, levantamento de demandas e tomadas de decisões pedagógicas e curriculares frente às necessidades da instituição, dos docentes e dos alunos (PIMENTA; ANASTASIOU, 2010).

Zabalza (2007) relata que, no exercício da docência, como atividade profissional, fazem-se necessários os conhecimentos docentes e os conhecimentos específicos. A docência não pode ser encarada como vocação em que se aprende a ser docente com experiências, sem preparação específica e formal. E conclui afirmando que:

Como consequência das mudanças ocorridas no cenário universitário, a docência sofreu também importantes transformações. A tradicional missão do docente como transmissor de conhecimentos ficou relegada a segundo plano, dando espaço ao seu papel de facilitador de aprendizagem de seus alunos. $O$ acesso ao conhecimento pode ser feito, hoje em dia, através dos mais diversos caminhos (livros, documentos de vários tipos, materiais em suporte informático, internet, etc.). Por outro lado, a facilidade de acesso não supõe auxílio à decodificação, à assimilação e ao aproveitamento desta informação, nem garante a vinculação desse material com a prática profissional. É justamente nessa função da "aprendizagem" (a mais genuinamente "formativa") que os professores universitários devem centrar sua ação (ZABALZA, 2007, p. 110). 
Almeida (2012) analisa que para entendermos o ensino como um exercício complexo e contextualizado na sociedade envolvida e avaliar quais os requisitos necessários para os que atuam profissionalmente é preciso pensar em:

a) concepções a respeito de si próprio e do seu papel social que dão sustentação à identidade profissional; b) componentes que integram os processos formativos, como teorias e práticas, conteúdos da área específica de atuação, conhecimentos didáticos-pedagógicos; c) contextos de formação e de trabalho; d) processos de construção do conhecimento e de seu desenvolvimento profissional (ALMEIDA, 2012, p. 73).

Igualmente, considerando que a formação inicial e continuada na área profissional da saúde são fundamentais para a profissionalização do supervisor de estágio de fisioterapia; que tais processos formativos influenciam demasiadamente a formação do futuro profissional fisioterapeuta, a formação do professor voltada às questões didático-pedagógicas se faz mister à formação do futuro profissional da área de Fisioterapia, porque ao transmitir conhecimentos fragmentados e descontextualizados das necessidades sociais sem confrontar teoricamente a prática pedagógica, o professor não consegue superar as formas tradicionais de ensino, frente às imposições de mudanças de paradigmas advindas das necessidades sociais.

\section{Consideraçōes finais}

Um dos objetivos do estudo foi investigar a formação pedagógica, a identidade e a profissionalização docente do supervisor de estágio dos cursos de Fisioterapia em Porto Velho-RO e as contribuições desses objetos para a formação profissional do fisioterapeuta. Podemos conferir que, de acordo com os documentos e a literatura pesquisada, nem a LDB 9394/96 e nem os Conselhos da área de Saúde deixam especificamente delimitado e exigido como os professores devem realizar a formação docente, para o exercício da profissão, já que a LDB preconiza a formação continuada do professor para ser realizada na pós-graduação, de preferência em mestrado ou doutorado, 
desconsiderando a formação inicial docente e o processo de formação formal em serviço.

Compreendemos que a formação pedagógica é imprescindível para a profissionalização docente e para a formação da identidade docente. A formação não se faz individualmente, esporadicamente ou por imposição institucional. É necessário um equilíbrio solidário entre as ações e esforços dos professores, o fomento e o apoio das IES e, principalmente, a regulação, supervisão e a avaliação do Estado, que também podem apoiar e fomentar, de forma a promover uma perspectiva formativa continuada, no mínimo, conforme a prescrita na LDB 9394/96.

Podemos observar com o estudo que geralmente prevalece a compreensão que a identidade e a profissionalização do professor ainda é considerada secundária, ficando centralizada nos conhecimentos técnicos da disciplina que está ministrando, sendo geralmente profissionalizado como professor do ensino superior pela reflexão da prática em sala de aula e o domínio dos conhecimentos pedagógicos da disciplina, com trocas de conhecimentos e princípios, coletivamente.

O fato de o futuro supervisor de estágio, enquanto ainda estudante, ter contribuições formativas docentes, ao observar o professor em sala de aula e ao apresentar trabalhos acadêmicos, realizando, assim, a formação e a profissionalização inicial docente pela experiência, não podemos admitir tal preceito costumeiro como justificativa para a falta de formação continuada aos professores de cursos de bacharelado, pois somente a experiência não supre as necessidades da formação inicial e da construção da identidade e profissionalização do supervisor de estágio.

Com relação ao supervisor de estágio que atua na área da Saúde, além do conhecimento teórico e do conhecimento didático-pedagógico, para melhor formar os futuros profissionais egressos dos cursos superiores, é necessário que seja promovida a formação docente para o envolvimento com as questões educacionais referentes às demandas da assistência e saúde da comunidade onde a IES está inserida e não somente atividades de reflexão da ação do professor, com aulas e dinâmicas, para envolverem 
interdisciplinarmente os estudantes nas atividades práticas formativas. É importante destacar que este é um desafio que vem sendo enfrentado por professores da área de Saúde e instituições, para superarem os métodos tradicionais de ensino e atenderem as demandas sociais, em coerência com as necessidades das DCN e do SUS.

Dessa maneira, estratégias de ensino, tanto do Ministério da Educação, como do Ministério da Saúde estão sendo propostas em prol da uniformidade da educação com a saúde, visando a melhoria no tratamento do cidadão e a formação do profissional generalista, humanista e com visão crítica e reflexiva (BRASIL, 2006), pontuando uma perspectiva para a identidade docente para o professor da área de Saúde.

Portanto, para atender a demanda de ensino da área de Saúde, professores e IES precisam abandonar o ensino tradicional, em que o docente é o detentor e centro do conhecimento. Precisam pesquisar e desenvolver formas de inovar no ensino, para transformar concepções e práticas formativas que se iniciam com teorias e, posteriormente, chegam às práticas, de maneira separada, sem confrontar teorias e práticas, sem estimular a crítica e sem desafiar o aluno frente aos conhecimentos empíricos e as realidades sociais construídas historicamente.

Na concepção tradicional de ensino, que o docente instrui, informa e repassa informações aos estudantes, com aulas previsíveis, não demanda pesquisa e ações reflexivas, pois o aluno fica na condição predominantemente de ouvinte, somente acatando as solicitações do docente, podendo influenciar o perfil do futuro profissional, como um sujeito pacífico, sem empatia e sem iniciativa.

Assim, uma Instituição que não apoia a formação continuada dos professores está manifestando uma posição política conservadora dentro do sistema capitalista, além de não favorecer o cumprimento do que determina a LDB 9394/96, para a formação a ser realizada na relação entre professores e alunos.

Um supervisor de estágio que não investe esforços ou não compreende a necessidade de investir esforços pessoais para a formação continuada, 
inclusive, aquela em serviço, também não cumpre a LDB 9394/96 e não manifesta responsabilidade e ética com a identidade e profissionalização docente.

O Estado, no modelo do sistema educacional, que é influenciado pelo sistema político-econômico de viés capitalista e privatista, acaba, por sua vez, somente criando mecanismos de regulação, supervisão e avaliação, que contribuem insuficientemente para a promoção da formação da docente e agem contra a construção da identidade e o estabelecimento da profissionalização docente, porque, mesmo que por meio de aplicação de exigências e obrigatoriedades sobre as IES públicas e privadas, acabam por reduzir os resultados da ação estatal à culpabilização dos professores pelos fracassos formativos.

Neste contexto, assentimos que é necessária a ressignificação pessoal, política e social acerca da importância e consequências da formação e profissionalização dos professores do Ensino Superior da Área de Saúde, para haver a institucionalização do comprometimento com a identidade docente a ser construída para se alcançar a formação generalista, crítica, reflexiva e humanizada dos egressos.

\section{Referências}

ALMEIDA, M. I. Formação de professor do ensino superior: desafios e políticas institucionais. São Paulo: Ed. Cortez, 2012.

BRANT, Victoria M.R. (Org.), O porquê e o para quê de um seminário sobre formação pedagógica de preceptores. In: Formação pedagógica de preceptores do ensino em saúde. Juiz de Fora: Ed. Juiz de Fora, 201 1. p. 5 -10.

BRASIL, lei n. 9394, de 20 de dezembro de 1996, Brasília, 1996.

BRASIL. Ministério da Educação, Ministério da Saúde. Aderência dos cursos de graduação em Enfermagem, Medicina e odontologia às diretrizes curriculares nacionais. Brasília: 2006.

BRZEZINSKI, I. (org.) Profissão professor: Identidade e profissionalização docente. Brasília: Plano editora, 2002.

DAY, C. Desenvolvimento profissional de professores: os desafios da aprendizagem permanente. Porto: Porto Editora, 2001. 
FORMOSINHO, J. Formação de professores - Aprendizagem profissional e ação docente. Porto: Porto Editora, 2009.

FRANCO, M. A. S. Prática docente universitária e a construção coletiva de conhecimentos: possibilidades de transformação. In: PIMENTA, S. G.,

ALMEIDA, M.I. (org.) Pedagogia universitária: caminhos para a formação de professores. São Paulo: Cortez, 2011.

LIBÂNEO, J.C. Conteúdos, formação de competências cognitivas e ensino com pesquisas: unindo ensino e modos de investigação. In: PIMENTA, S. G., ALMEIDA, M.I.(org.) Pedagogia universitária: caminhos para a formação de professores. São Paulo: Cortez, 2011.

MASETTO, M.T. Competência pedagógica do professor universitário. $2^{a}$ Ed. rev., São Paulo: Summus, 2012.

PERRENOUD, P. Competências para ensinar no século XXI: A formação de professores e o desafio da avaliação. Porto Alegre: Artmed, 2007.

PIMENTA, S. G., ANASTASIOU, L. G. C. Docência no Ensino Superior. $5^{a}$ ed. São Paulo: Cortez, 2014.

VEIGA, I. P. A. A docência na Educação Superior e as didáticas especiais: campos em construção, Rev. Educação, Santa Maria, v. 36, n. 3, p. 455-464, set./dez. 2011.

ZABALZA, M. A. O ensino universitário: seu cenário e seus protagonistas. Porto Alegre: Ed. Artimed, 2007.

Recebido em: 27 de agosto de 2020 Aprovado em: 14 de setembro de 2020 Publicado em: 14 de setembro de 2020 